\title{
Mediação da leitura e literatura na educação infantil para o desenvolvimento integral
}

\author{
Reading mediation and literature mediation in early childhood education for the integral \\ development
}

Ana Caroline Abreu

Graduada em Pedagogia pela Universidade do Contestado e graduanda do curso de Biblioteconomia pela Universidade Comunitária da Região de Chapecó - UNOCHAPECÓ, Brasil. Professora na Prefeitura Municipal de Curitibanos. https://orcid.org/0000-0002-0764-7662 E-mail: ana.carolineabreu@ hotmail.com

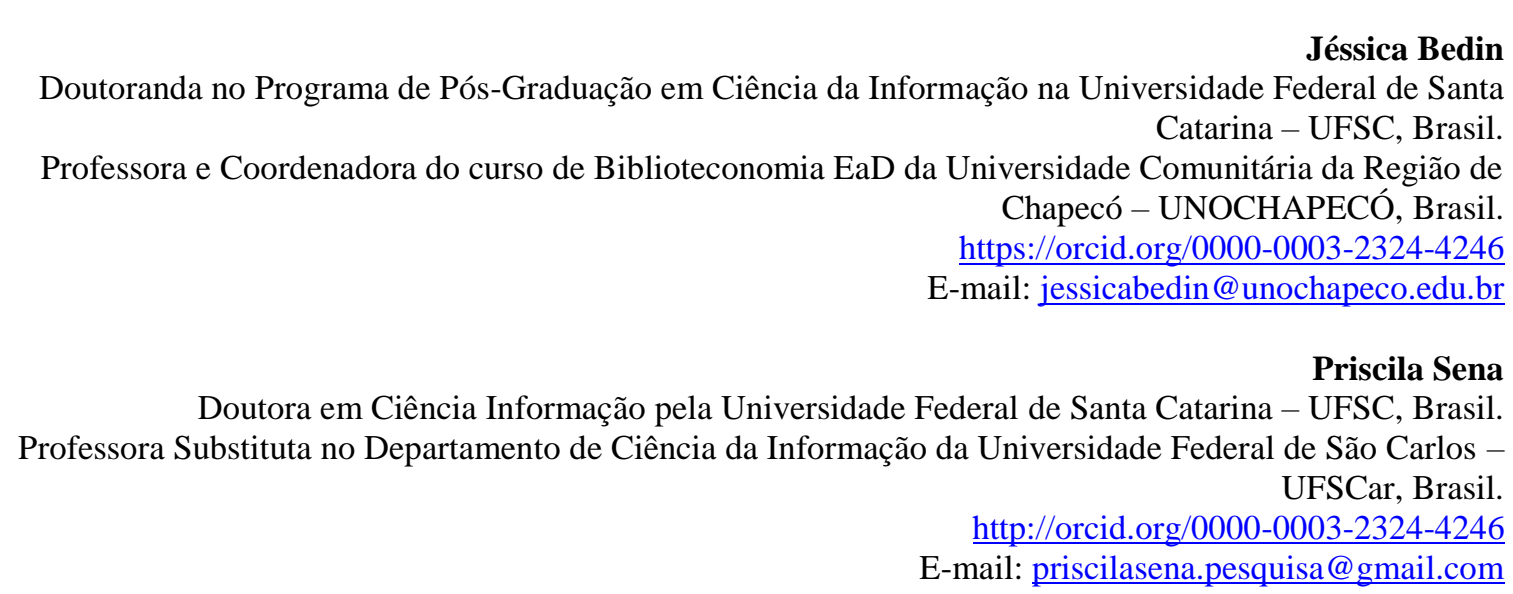

\section{Resumo}

Apresenta pesquisa cujo objetivo consistiu em analisar a literatura infantil e sua mediação no desenvolvimento integral da criança, de acordo com a Base Nacional Comum Curricular (BNCC) para o desenvolvimento integral da criança de 0 a 5 anos. Trata-se de pesquisa bibliográfica documental com abordagem qualitativa, a partir da busca na Base de Dados em Ciência da Informação (BRAPCI) onde recuperou-se documentos pelos termos mediação da leitura e mediação da literatura para obter a conceituação e as práticas de mediação em bibliotecas e com análise documental do documento Base Nacional Comum Curricular para obter subsídios do que é a formação integral do sujeito. Observa-se que existem na literatura científica conceituações incipientes quanto a diferenciação entre mediação da leitura e mediação da literatura, contudo, elas são diferentes, pois enquanto a mediação da leitura envolve aspectos da alfabetização, mediação da literatura aborda práticas que relacionam ao conhecimento de mundo e lazer. No que tange às práticas realizadas em bibliotecas, podem ser adaptadas e embasadas nos objetivos da BNCC para o desenvolvimento integral para crianças de 0 a 5 anos, que são o foco deste estudo, a partir da literatura infantil e mediação da literatura. Por meio da literatura infantil e sua mediação em biblioteca escolar é possível iniciar o desenvolvimento integral de crianças de 0 a 5 anos. Com práticas alinhadas aos objetivos da BNCC, adaptando-se às atividades para a respectiva faixa etária, pode-se ter a formação de sujeitos críticos e capazes de se desenvolverem plenamente no âmbito educacional.

Palavras-chave: Biblioteca escolar. Literatura infantil. Desenvolvimento integral. Base Nacional Comum Curricular-BNCC.

InCID: R. Ci. Inf. e Doc., Ribeirão Preto, v. 12, n. 2, p. 89-108, set. 2021./fev. 2022. 


\begin{abstract}
It presents research whose objective is to analyze children's literature and its mediation in the integral development of the child, according to the Common National Curricular Base (BNCC) for the integral development of children from 0 to 5 years. It is documental bibliographic research with a qualitative approach, from the search in the Database on Information Science (BRAPCI) where documents were recovered by the terms mediation of reading and mediation of literature to obtain the conceptualization and practices of mediation in libraries and with documental analysis of the document Common National Curriculum Base to obtain subsidies of what is the subject's full education. It is observed that there are incipient concepts in the scientific literature regarding the differentiation between reading mediation and literature mediation, however, they are different, because while reading mediation involves aspects of literacy, literature mediation addresses practices that relate to knowledge of the world and leisure. Concerning practices carried out in libraries, they can be adapted and based on the BNCC objectives for the integral development of children from 0 to 5 years of age, which are the focus of this study, from children's literature and literature mediation. Through children's literature and its mediation in school libraries, it is possible to initiate the integral development of children from 0 to 5 years old. With practices aligned with the objectives of the BNCC, adapting to activities for the respective age group, it is possible to have the formation of critical subjects capable of fully developing in the educational field.
\end{abstract}

Keywords: School library. Children's literature. Integral development. Common National Curricular Base BNCC.

\title{
1. Introdução
}

A literatura infantil na primeira infância é uma ferramenta que possibilita o desenvolvimento de muitos aspectos, desde cognitivos a físicos, porém é um desafio utilizá-la de forma que seja espontânea para criança, sem o viés da alfabetização, como a abordagem de um assunto específico ou o reconhecimento de letras, enfim, formas escolarizadas de uso. $\mathrm{O}$ ideal é que na infância se forme o hábito da leitura e por meio dela se torne capaz de despertar sentidos, encantamento, diálogos, dando significados ao mundo da imaginação, além de ser objeto cultural que vai desenvolver o lado crítico através da sensibilidade (SILVA, 1998).

Para que a literatura seja apresentada a criança, que aqui abrange o público de 0 a 5 anos, pode-se utilizar da mediação, importante instrumento para inserção da criança no mundo literário. É o entrelaçamento entre o leitor e o livro, construindo uma relação social de interação. Neste processo, o profissional que faz esta intervenção precisa saber que "mediar a leitura é fazer fluir a indicação ou o próprio material de leitura até o destinatário-alvo, eficiente e eficazmente, formando leitores" (BARROS, 2006, p. 17), portanto, promover o encontro entre o leitor em formação e o texto literário.

A partir dessa compreensão, torna-se pertinente atentar ao fato de que hoje, a finalidade da educação é o desenvolvimento pleno do educando em todas suas dimensões, como a intelectual, social, emocional e simbólica, sem fragmentação dos componentes curriculares. E 
principalmente que tenham sentido para o estudante, que crie pontes entre o conhecimento e a vida, com o "protagonismo do estudante em sua aprendizagem e na construção de seu projeto de vida" (BRASIL, 2017, p. 15).

Ademais, faz-se necessário assegurar que se contemple um conjunto de capacidades desde a educação infantil para o pleno desenvolvimento de crianças, para que estes se tornem cidadãos críticos e conscientes. Dessa forma questiona-se: Como a mediação da literatura na educação infantil pode estimular o desenvolvimento integral?

Convém então pensar que a literatura infantil sendo mediada por um profissional desde a primeira infância, com práticas adequadas à idade e na biblioteca escolar, pode vir a contribuir com o desenvolvimento integral do sujeito, pois este é um período rico de evolução cognitiva, afetiva e de compreensão de mundo.

Posto isso, nesta pesquisa o objetivo geral é analisar a literatura infantil e sua mediação no desenvolvimento integral da criança, de acordo com a Base Nacional Comum Curricular (BNCC). Assim, com os objetivos específicos almeja-se a) compreender a Base Nacional Comum Curricular (BNCC) para educação infantil; b) descrever a mediação da leitura e da literatura em biblioteca e; c) identificar práticas de mediação de leitura e literatura em biblioteca.

Ao compreender que a literatura infantil traz em sua essência aspectos éticos e estéticos, capaz de promover o conhecimento de si e do mundo, pressupõe-se seu potencial de abrir caminhos para o desenvolvimento íntegro da criança.

Na perspectiva da Base Nacional Comum Curricular (BNCC), documento que permeia a educação nacional, documento recente, homologado em 2017, requer olhar atento, assim, este artigo vem a contribuir na compreensão dos novos conceitos e para que a mediação em bibliotecas escolares com crianças seja mais significativa, oferecendo subsídios para seu desenvolvimento durante o percurso na educação infantil.

Portanto, nesta pesquisa procura-se alicerces para afirmar a contribuição da literatura infantil e de boas práticas de mediação em bibliotecas escolares no sentido de repercutir no desenvolvimento e consequentemente impactando na vida dos sujeitos.

O artigo se divide em seções a iniciar pela introdução, partindo para os procedimentos metodológicos com as técnicas e métodos utilizados ao longo deste trabalho. Seguindo com o referencial teórico com uma seção dedicado à literatura infantil, outra ao desenvolvimento 
integral e a última para os conceitos de mediação de leitura e literatura. Finalizando com a análise dos resultados e os desencadeamentos ao término da pesquisa com as considerações finais. Seguem então as referências que avalizam este trabalho.

\section{Procedimentos metodológicos}

No que concerne aos procedimentos metodológicos, esta pesquisa pode ser classificada como exploratória, que "objetiva proporcionar maior familiaridade com o problema, com vista a torná-lo mais explícito ou a construir hipóteses" (GIL, 2002 p. 41) e descritiva, onde a partir da exploração, estabelece relações entre as variáveis estudando as características de determinado grupo para classificar conceitos.

A análise dos resultados é de abordagem qualitativa, que se refere a uma sequência de atividades que envolve a relação dos dados, a categorização destes dados e sua interpretação para a construção da redação da pesquisa (GIL, 2002).

Quanto aos procedimentos técnicos trata-se de uma pesquisa bibliográfica com análise documental. Na pesquisa de caráter bibliográfico o pesquisador busca entrar em contato com materiais já existentes sobre o assunto para subsidiar seu estudo (MARCONI; LAKATOS, 2002), sendo assim,

[...] é desenvolvida com base em material já elaborado, constituído principalmente de livros e artigos científicos. Embora em quase todos os estudos seja exigido algum tipo de trabalho dessa natureza, há pesquisas desenvolvidas exclusivamente a partir de fontes bibliográficas (GIL, 2002, p. 44).

Posta assim a questão, desenvolve-se o estudo por meio de pesquisa na Base de Dados em Ciência da Informação (BRAPCI), com a busca dos termos "mediação da leitura" com 29 documentos recuperados e "mediação da literatura" com 7 documentos recuperados.

Na próxima seção encontra-se a análise de como ocorre a mediação da literatura infantil nas bibliotecas escolares identificando as práticas desenvolvidas nestes ambientes, se é relevante para o desenvolvimento integral das crianças.

Por conseguinte, tem-se o delineamento documental, que segundo Gil (2002, p.46) "há que se considerar que os documentos constituem fonte rica e estável de dados. Como os documentos subsistem ao longo do tempo, tornam-se a mais importante fonte de dados em qualquer pesquisa de natureza histórica". 
Sendo assim, parte-se do mais recente documento voltado para educação nacional, a Base Nacional Comum Curricular (BNCC), que traz novos conceitos e rumos, dentre eles o que mais nos interessa neste estudo: a formação integral do sujeito, na perspectiva da educação infantil.

Para tanto, também se explora a Lei de Diretrizes e Bases (LDB), especificamente para a seção que diz respeito a educação infantil, para conhecermos um pouco das especificidades desta etapa de ensino.

A fim de atentar o olhar de como a literatura infantil pode contribuir para esta formação integral principalmente no ambiente da biblioteca escolar, agrega-se as diretrizes da Federação Internacional de Associações e Instituições Bibliotecárias (IFLA) para bibliotecas escolares.

Para atender ao objetivo A realizou-se análise documental para a compreensão do que se trata a Base Nacional Comum Curricular nos aspectos voltados para a etapa do ensino básico da educação infantil.

Já no objetivo B, efetuou-se uma pesquisa bibliográfica a partir de uma busca na Base de Dados em Ciência da Informação (BRAPCI) ${ }^{1}$ com os termos "mediação da leitura" e "mediação da literatura", delimitando-se a palavras-chave em português, com a recuperação de 36 arquivos, sendo divididos entre os que apresentaram os conceitos de mediação da leitura e mediação da literatura e os que não trouxeram os conceitos, como apresentado na figura 1.

Figura 1 - Recuperação e seleção dos artigos sobre mediação da leitura e literatura

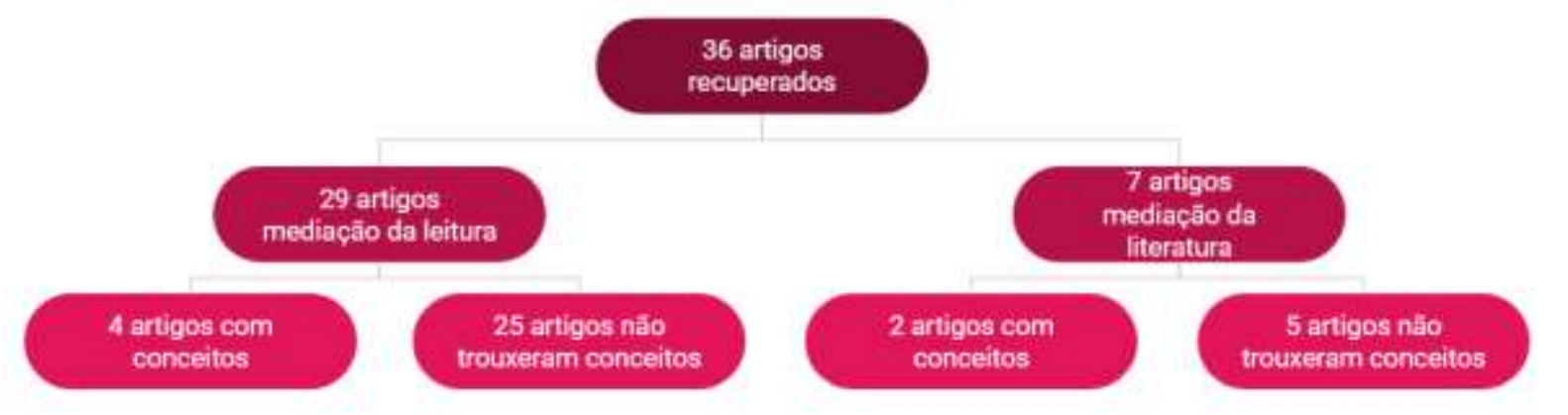

Fonte: Dados da pesquisa (2020).

Por conseguinte, no que tange a literatura, extraiu-se os conceitos e diferenças entre termos que serão analisados. No objetivo C, buscou-se, a partir dos artigos recuperados,

\footnotetext{
${ }^{1}$ Mais informações em: http://www.brapci.ufpr.br/brapci/index.php/home. 
identificar práticas de mediação em bibliotecas, que venham atentar-se ao público da educação infantil, com respaldo nos campos de experiências da BNCC.

Nas seções que se seguem são abordadas as temáticas da literatura infantil, mediação da literatura e a contribuição no desenvolvimento integral, enquanto base teórica. Iniciando com a abordagem do gênero literatura infantil para crianças de 0 a 5 anos.

\section{Literatura infantil}

A literatura infantil como gênero literário abrange aspectos específicos como uso de imagens e textos curtos, no entanto ela não tem menor valor que outros gêneros. Devido a compartimentação da literatura, que vem sendo distribuída em "caixas" muitas vezes é considerada inferior (LAJOLO; ZILBERMAN, 1999), no entanto,

a literatura é uma das produções humanas mais importantes para a formação do indivíduo, pois sua matéria é a palavra, o pensamento e as idéias, exatamente aquilo que define a especificidade do ser humano. A criança deve ter acesso à literatura, associando e harmonizando a fantasia e a realidade, a fim de satisfazer suas exigências internas e desejos imaginários. A proposta da literatura infantil é que seja desenvolvida a emoção, a sensibilidade, a imaginação e a fantasia da criança (SILVA, 2009, p.122).

Desta forma, a literatura que possui uma multiplicidade de códigos, suportes, textualidades, vem sendo segmentada ao longo da escolarização por faixa etária, utilizada didaticamente a fim de alfabetizar ou instruir determinado assunto (SOUZA, 2014).

Neste contexto, as múltiplas possibilidades que a literatura traz não são exploradas em sua potencialidade, ainda mais desde a primeira infância, onde as crianças não se encontram alfabetizadas, no entanto a leitura tem suas raízes na complexa atividade interpretativa que o ser humano desenvolve desde seu ingresso no mundo simbólico (REYES, 2010).

A primeira infância, que vai desde o nascimento aos 6 anos de idade e abrange os bebês, crianças bem pequenas e crianças pequenas (BRASIL, 2017) é uma fase rica em aprendizado, pois nesta etapa a criança é um ser ativo estabelecendo conexões de troca de conhecimento através das relações vivenciadas que são significativas, resultado de laços dela com o meio físico e social que está inserida (PIAGET, 1973). Conforme Piaget, de fato o conhecimento é fruto das trocas entre o organismo e o meio e essas trocas são responsáveis pela construção da própria capacidade de conhecer. 
Sendo assim, partindo da utilização da literatura para a formação do sujeito, sem o foco da alfabetização (que será no futuro uma consequência do acesso ao mundo literário desde bebê), por meio das primeiras relações de leitura como processo de comunicação e interação, é considerável que ela estimula a imaginação, bem como,

ao ler uma história a criança também desenvolve todo um potencial crítico. A partir daí ela pode pensar, duvidar, se perguntar, questionar. Pode se sentir inquietada, cutucada, querendo saber mais e melhor ou percebendo que se pode mudar de opinião... E isso não sendo feito uma vez ao ano... Mas fazendo parte da rotina escolar, sendo sistematizado, sempre presente (ABRAMOVICH, 1989, p.143).

Inclusive, por meio da imaginação, a criança permite-se ser outras pessoas além dela mesma, descobrindo que pode sonhar, nomear, encontrar outros universos e decifrar a nós mesmos (REYES, 2010), e ainda

a imaginação está presente nas narrativas durante o desenvolvimento humano. Por
isso, as histórias devem ser narradas desde a mais tenra idade não como processo
educativo ou doutrinário, pois a verdade deve se transformar no fundamento da
educação, mas sim como arte e estética, no âmbito da lei da realidade emocional da
fantasia. As narrativas constituem modos de mediação que poderiam estar presentes
em todos os processos do desenvolvimento do ser humano (MORO; ESTABEL, 2011,
p.79).

Até o momento percebe-se importante a inserção da literatura para o desenvolvimento humano, e dentro da escola, a biblioteca é o local mais propício a este contato, sem fins canônicos. Assim, o desenvolvimento de ações na biblioteca para este público auxilia estes pequenos interagentes a ampliar suas habilidades e competências enquanto processo de compreensão de mundo, de construção de sujeitos ativos em sociedade, preparando-os culturalmente para tornarem-se protagonistas de suas vidas.

Devemos atentar-se ao fato de que ninguém nasce sabendo ler, aprende-se a ler na medida em que se vive, conforme Freire (1988) elucidou ao afirmar que a leitura de mundo precede a leitura da palavra, e assim se efetiva em uma relação dinâmica que vincula linguagem, realidade, imaginação, afetividade e percepção de mundo.

Desta forma, não é necessário estar alfabetizado para trabalhar o desenvolvimento integral na educação infantil, visto que este conceito do desenvolvimento é fundamental dentro das bibliotecas escolares, pois é concretizado a partir do documento que traz as perspectivas para a educação nacional, a BNCC. 


\section{Desenvolvimento integral}

Durante anos estudos foram desenvolvidos para a criação de um novo documento que norteasse a educação no país, que respeitasse as diversidades e trabalhasse para o desenvolvimento integral dos estudantes. Todavia, somente em dezembro de 2017 foi homologada a Base Nacional Comum Curricular para a educação infantil e ensino fundamental e no ano seguinte, a parte que trata do ensino médio.

Este documento é uma ferramenta para a educação nacional que estabelece objetivos de aprendizagem em cada etapa de ensino, estes devem ser alcançadas por meio de competências e habilidades (BRASIL, 2017). Para isso, serve como orientação para elaboração do currículo escolar de cada instituição, levando em consideração as especificidades de cada região, para traçar estratégias pedagógicas mais adequadas ao ensino aprendizagem de seus educandos.

As mudanças trazidas neste documento têm o objetivo de desenvolvimento integral dos sujeitos, sendo esta uma concepção que compreende a garantia do desenvolvimento em todas suas dimensões: intelectual, física, emocional, social e cultural, na centralidade do aluno em seu processo de ensino (BRASIL, 2017).

Convém então pensarmos este desenvolvimento desde os primeiros anos do estudante inserido na escola, iniciando na educação infantil. A Lei de Diretrizes e Bases da Educação Nacional 9394/96 tem descrito em seu artigo 29 que "a primeira etapa da educação básica tem como finalidade o desenvolvimento integral da criança até seis anos de idade, em seus aspectos físico, psicológico, intelectual e social, complementando a ação da família e da comunidade" (BRASIL, 1996, p. 22).

Conforme a LDB, esta etapa abrange crianças de até três anos na categoria creche e de quatro a cinco anos na pré-escola. É importante compreendermos a definição das faixas etárias, a BNCC define como "bebês quem possui de zero a um ano e seis meses, crianças bem pequenas de um ano e sete meses a três anos e onze meses e crianças pequenas as de quatro anos a cinco anos e onze meses" (BRASIL, 2017, p. 44).

Sendo assim, a BNCC traz os parâmetros para o desenvolvimento da educação infantil, partindo dos campos de experiências, sendo eles: o eu, o outro e o nós; corpo, gestos e movimentos; traços, sons, cores e formas; escuta, fala, pensamento e imaginação; espaços, tempos, quantidades, relações e transformações. Cada campo possui seus objetivos a serem 
alcançados ao longo da educação infantil, aliado aos seis direitos de aprendizagem e desenvolvimento, que são o conviver, brincar, participar, explorar, expressar e conhecer-se (BRASIL, 2017).

Por se tratar de um documento recente, poucos estudos já foram publicados, cabe então uma análise de como, afinal, pode-se desenvolver este sujeito íntegro, logo com início da sua trajetória na educação infantil.

Nesta pesquisa, busca-se amparo na mediação da literatura para conduzir e contribuir com o desenvolvimento integral na educação infantil, dessa forma, na próxima seção são apresentados alguns conceitos para diferenciar a mediação da leitura da mediação da literatura.

\section{Mediação de leitura e literatura}

Para compreender a diferença entre a mediação da leitura e da literatura, é necessário buscar suporte nos conceitos teóricos e entender suas características. Desta forma, realizou-se a busca dos termos na base de dados BRAPCI, onde foi possível analisar, por meio da recuperação da literatura científica, que a mediação da leitura acontece diferente da mediação da literatura.

Enquanto a primeira é um instrumento voltado para prática de alfabetização, para domínios dos códigos sociais, o segundo termo é direcionado para questões culturais, ampliação do conhecimento, curiosidade, imaginação, desvinculada ao trabalho de alfabetização escolar. Então, direciona-se o olhar para mediação da literatura, mas não excluindo a mediação da leitura, pois intrinsecamente ela está presente no cotidiano das crianças, através da mediação dos adultos.

Parte-se da ideia de que desde o nascimento é inevitável que precisemos de mediadores para atividades cotidianas, para a inserção no mundo literário não é diferente, visto que se tratando da mediação da leitura literária, ela ocorre quando um indivíduo apresenta a outro um livro, texto ou narração, que vai introduzi-lo no universo da literatura.

Conforme Piaget (1973) o conhecimento é fruto das trocas entre o organismo e o meio e essas trocas são responsáveis pela construção da própria capacidade de conhecer. Ademais, Vygotsky (2007) afirma que o homem não se relaciona com o mundo de forma direta, se relaciona de forma mediada por instrumentos materiais e psicológicos. Instrumentos esses que 
vão proporcionar para criança na biblioteca escolar contato com a literatura a partir da mediação do bibliotecário, onde ocorrerão "transformações comportamentais que estabelecem um elo de ligação entre as formas iniciais e tardias do desenvolvimento individual" (VYGOTSKY, 2007, p. 26). Então, é por intermédio da mediação, da intervenção, que profissionais de Biblioteconomia podem promover o interesse e a curiosidade para o mundo literário.

A importância da mediação da literatura nas bibliotecas é exposta no documento Retratos de Leitura no Brasil. Conforme o estudo, o interesse pela literatura na infância se inicia pela influência da mãe ou responsável do sexo feminino atinge $32 \%$ e por influência do pai ou responsável do sexo masculino, 20\% (INSTITUTO PRÓ-LIVRO, 2020). Ainda conforme o documento, a efetivação dessa mediação para aqueles que não fazem parte desta parcela que tem em casa o contato com a literatura, vem através da escola e da biblioteca escolar.

Dentro da instituição de ensino, em especial na biblioteca escolar, além do incentivo e prática dos professores, que fazem o uso da mediação da leitura voltado a instrumentalização do código escrito, é na biblioteca que a criança vai se deparar com a magia da literatura. Neste espaço, o mediador é a bibliotecária ou o bibliotecário, que, com o uso de embasamento teórico em suas práticas, vai atuar para que a mediação seja uma ferramenta a mais no processo de desenvolvimento cognitivo, afetivo e físico da criança.

Esta ação de mediação envolve o entrelaçamento entre o leitor e a leitura literária, e, quando se trata de literatura para crianças, ganha aspectos da ludicidade, voltada para despertar a curiosidade, criticidade, imaginação, criatividade, desvinculada a leitura da escolarização.

Sendo assim, as atividades realizadas na biblioteca escolar devem levar em consideração que a leitura literária,

em função de suas especificidades, deve ser refletida e praticada dentro de uma perspectiva ampla, que tem como pano de fundo o conjunto de estratégias e ações de organização e dinamização da biblioteca escolar considerada ambiente profícuo ao processo de mediação (SOUZA, 2014 p. 6).

Tratando dos conceitos, recuperou-se 36 artigos científicos, no entanto, encontrando os conceitos em apenas 6, datados de 2009 a 2019. Ademais, no quadro 1, estão elencadas as definições de mediação da leitura e no quadro 2, elencados as de mediação da literatura. 
Quadro 1 - Conceitos de mediação da leitura

\begin{tabular}{|l|l|}
\hline Autores & Mediação da leitura \\
\hline Souza (2014) & $\begin{array}{l}\text { Instrumento pedagógico cultural, focado em um processo de mediação que visa, em } \\
\text { útima análise, a instrumentalizar o leitor na proficiência da leitura. }\end{array}$ \\
\hline $\begin{array}{l}\text { Bortolin, Almeida } \\
\text { Júnior (2014) }\end{array}$ & $\begin{array}{l}\text { A mediação da leitura, para Bortolin (2010), é uma atividade da qual o bibliotecário não } \\
\text { pode se esquivar, visto que o ato de ler precede o ato de se informar, descobrir e } \\
\text { investigar. }\end{array}$ \\
\hline $\begin{array}{l}\text { Costa e Santos Neto } \\
(2016)\end{array}$ & $\begin{array}{l}\text { A mediação da leitura, é um processo em que o profissional da informação tem a } \\
\text { "responsabilidade de acompanhar um leitor durante a sua formação ou mesmo depois } \\
\text { de formado (na medida em que a formação é contínua) quando em dúvida ou } \\
\text { desencorajado, solicita uma sugestão" (ALMEIDA JÚNIOR; BORTOLIN, 2007, p.8) }\end{array}$ \\
\hline $\begin{array}{l}\text { Amaro e Alencar } \\
(2017)\end{array}$ & $\begin{array}{l}\text { Barros (2006, p. 17) aponta que "[...] mediar a leitura é fazer fluir a indicação ou o } \\
\text { próprio material de leitura até o destinatário-alvo, eficiente e eficazmente, formando } \\
\text { leitores.” }\end{array}$ \\
\hline
\end{tabular}

Fonte: Dados da pesquisa (2020).

Quadro 2 - Conceitos de mediação da literatura

\begin{tabular}{|l|l|}
\hline Autores & Mediação da literatura \\
\hline Silva (2009) & $\begin{array}{l}\text { A mediação da leitura literária ocorre quando um indivíduo (nas mais variadas faixas } \\
\text { etárias) apresenta a outro indivíduo um texto, um livro, um CD, um filme ou narra um } \\
\text { texto literário. }\end{array}$ \\
\hline Antunes et al. (2019) & $\begin{array}{l}\text { Bortolin (2010, p. 137), "é toda intervenção espontânea ou planejada de um mediador } \\
\text { de leitura visando a aproximar o leitor-ouvinte de textos literários seja por meio da voz } \\
\text { viva ou da voz mediatizada." }\end{array}$ \\
\hline
\end{tabular}

Fonte: Dados da pesquisa (2020).

Constatou-se quatro conceitos para mediação da leitura e dois para mediação da literatura. Acredita-se que o fato de que ambos são considerados sinônimos corrobora para este resultado.

Desta forma, considera-se fundamental o profissional estar preparado, ter conhecimento da área de atuação, conceitos, dos documentos que regem a instituição de ensino a qual está inserido, e que conheça a literatura infantil mais a fundo, pois ela contém nuances em sua estrutura a ser observado, além de ser rica em detalhes para que o imaginário infantil seja explorado. 


\section{Práticas de mediação de leitura e literatura em bibliotecas}

Utilizando-se ainda a busca na base de dados BRAPCI pelos termos "mediação da leitura" e "mediação da literatura", relaciona-se no quadro 3 os artigos que apresentam efetivamente práticas de mediação em bibliotecas. O quadro 3 se estrutura com a apresentação dos autores em ordem cronológica, sendo o artigo mais antigo datado de 2009 e os mais recentes de 2020. Seguindo com a lista das práticas de mediação desenvolvidas em bibliotecas que são relatadas dentro destes artigos, para então relacioná-las e alinhá-las às práticas da BNCC para a educação infantil.

As práticas alinhadas com a BNCC são estruturadas com a utilização de códigos alfanuméricos, como este exemplo: EI02TS01. O primeiro par de letras indica a educação infantil $=$ EI. $\mathrm{O}$ primeiro par de números indica o grupo por faixa etária: $01=$ Bebês (zero a 1 ano e 6 meses) $02=$ Crianças bem pequenas ( 1 ano e 7 meses a 3 anos e 11 meses) $03=$ Crianças pequenas (4 anos a 5 anos e 11 meses). O segundo par de letras indica o campo de experiências: $\mathrm{EO}=\mathrm{O}$ eu, o outro e o nós; $\mathrm{CG}=$ Corpo, gestos e movimentos; $\mathrm{TS}=$ Traços, sons, cores e formas; $\mathrm{EF}=$ Escuta, fala, pensamento e imaginação; $\mathrm{ET}=$ Espaços, tempos, quantidades, relações e transformações. E o último par de números indica a posição da habilidade na numeração sequencial do campo de experiências para cada grupo/faixa etária (BNCC, 2017).

Quadro 3 - Práticas desenvolvidas em bibliotecas (continua)

\begin{tabular}{|c|c|c|}
\hline Autores & Práticas De Mediação & Prática Alinhada a BNCC \\
\hline Silva (2009) & Hora do conto & $\begin{array}{l}\text { Demonstrar interesse ao ouvir histórias lidas ou contadas, } \\
\text { observando ilustrações e os movimentos de leitura do adulto- } \\
\text { leitor (modo de segurar o portador e de virar as páginas) } \\
\text { (EI01EF03). }\end{array}$ \\
\hline $\begin{array}{l}\text { Rasteli e } \\
\text { Cavalcante } \\
(2014)\end{array}$ & $\begin{array}{l}\text { Hora do conto; } \\
\text { Encontro com autores e } \\
\text { lançamento de livros; } \\
\text { Concursos e saraus } \\
\text { literários; } \\
\text { Homenagem a autores; } \\
\text { Exposição de livros; } \\
\text { Dramatização de histórias } \\
\text { (teatro); Sessões de cinema } \\
\text { na biblioteca; Encontro com } \\
\text { cordelistas }\end{array}$ & $\begin{array}{l}\text { Demonstrar interesse ao ouvir histórias lidas ou contadas, } \\
\text { observando ilustrações e os movimentos de leitura do adulto- } \\
\text { leitor (modo de segurar o portador e de virar as páginas) } \\
\text { (EI01EF03). } \\
\text { Interagir com outras crianças da mesma faixa etária e adultos, } \\
\text { adaptando-se ao convívio social (EI01EO06). } \\
\text { Ampliar as relações interpessoais, desenvolvendo atitudes de } \\
\text { participação e cooperação (EI03EO03). } \\
\text { Recontar histórias ouvidas e planejar coletivamente } \\
\text { roteiros de vídeos e de encenações, definindo os contextos, os } \\
\text { personagens, a estrutura da história (EI03EF04). } \\
\text { Selecionar livros e textos de gêneros conhecidos para a leitura } \\
\text { de um adulto e/ou para sua própria leitura (partindo de seu } \\
\text { repertório sobre esses textos, como a recuperação pela } \\
\text { memória, pela leitura das ilustrações, etc.) (EI03EF08). } \\
\text { Criar com o corpo formas diversificadas de expressão de } \\
\text { sentimentos, sensações e emoções, tanto nas situações do }\end{array}$ \\
\hline
\end{tabular}




\begin{tabular}{|c|c|c|}
\hline Autores & Práticas De Mediação & Prática Alinhada a BNCC \\
\hline & & $\begin{array}{l}\text { cotidiano quanto em brincadeiras, dança, teatro, música } \\
\text { (EI03CG01). } \\
\text { Relatar experiências e fatos acontecidos, histórias ouvidas, } \\
\text { filmes ou peças teatrais assistidos (EI02EF05). } \\
\text { Observar e descrever mudanças em diferentes materiais, } \\
\text { resultantes de ações sobre eles, em experimentos envolvendo } \\
\text { fenômenos naturais e artificiais (EI03ET02). }\end{array}$ \\
\hline $\begin{array}{l}\text { Gomes e } \\
\text { Santos (2014) }\end{array}$ & $\begin{array}{l}\text { Oficina de leitura; } \\
\text { Levantamento } \\
\text { bibliográfico (indicação de } \\
\text { leituras); } \\
\text { Treinamento para uso de } \\
\text { base de dados; } \\
\text { Disseminação seletiva da } \\
\text { informação; } \\
\text { Semana da escrita científica; } \\
\text { Treinamento para } \\
\text { elaboração de trabalhos } \\
\text { acadêmicos; } \\
\text { Workshops de capacitação } \\
\text { de } \\
\text { pesquisadores } \\
\text { publicação científica. para }\end{array}$ & \\
\hline $\begin{array}{l}\text { Costa e Santos } \\
\text { Neto (2016) }\end{array}$ & $\begin{array}{l}\text { Sarau; } \\
\text { Teatro; } \\
\text { Recreações; } \\
\text { Contação de histórias }\end{array}$ & $\begin{array}{l}\text { Demonstrar interesse ao ouvir a leitura de poemas e a } \\
\text { apresentação de músicas (EI01EF02). } \\
\text { Inventar brincadeiras cantadas, poemas e canções, criando } \\
\text { rimas, aliterações e ritmos (EI03EF02). } \\
\text { Criar com o corpo formas diversificadas de expressão de } \\
\text { sentimentos, sensações e emoções, tanto nas situações do } \\
\text { cotidiano quanto em brincadeiras, dança, teatro, música } \\
\text { (EI03CG01). } \\
\text { Ampliar as relações interpessoais, desenvolvendo atitudes de } \\
\text { participação e cooperação (EI03EO03). } \\
\text { Criar e contar histórias oralmente, com base em imagens ou } \\
\text { temas sugeridos (EI02EF06). }\end{array}$ \\
\hline $\begin{array}{l}\text { Amaro } \quad \text { e } \\
\text { Alencar } \\
(2017)\end{array}$ & $\begin{array}{l}\text { Oficinas; } \\
\text { Exposições; } \\
\text { Narração de histórias; } \\
\text { Rodas de leitura; } \\
\text { Clubes de leitura; } \\
\text { Mostra de filmes; } \\
\text { Feiras e festas literárias; } \\
\text { Cafés literários. }\end{array}$ & $\begin{array}{l}\text { Explorar o ambiente pela ação e observação, manipulando, } \\
\text { experimentando e fazendo descobertas (EI01ET03). } \\
\text { Participar de situações de escuta de textos em diferentes } \\
\text { gêneros textuais (poemas, fábulas, contos, receitas, quadrinhos, } \\
\text { anúncios etc.) (EI01EF08). } \\
\text { Selecionar livros e textos de gêneros conhecidos para a leitura } \\
\text { de um adulto e/ou para sua própria leitura (partindo de seu } \\
\text { repertório sobre esses textos, como a recuperação pela } \\
\text { memória, pela leitura das ilustrações, etc.) (EI03EF08). } \\
\text { Relatar experiências e fatos acontecidos, histórias ouvidas, } \\
\text { filmes ou peças teatrais assistidos (EI02EF05). } \\
\text { Compartilhar os objetos e os espaços com crianças da mesma } \\
\text { faixa etária e adultos (EI02EO03). }\end{array}$ \\
\hline Fleck (2018) & Contação de histórias & $\begin{array}{l}\text { Demonstrar interesse ao ouvir histórias lidas ou contadas, } \\
\text { observando ilustrações e os movimentos de leitura do adulto- } \\
\text { leitor (modo de segurar o portador e de virar as páginas) } \\
\text { (EI01EF03). }\end{array}$ \\
\hline Fleck, Cunha & Pequenas sessões cênicas; & Perceber as possibilidades e os limites de seu corpo nas \\
\hline
\end{tabular}




\begin{tabular}{|c|c|c|}
\hline Autores & Práticas De Mediação & Prática Alinhada a BNCC \\
\hline $\begin{array}{l}\text { e Navarra } \\
(2018)\end{array}$ & $\begin{array}{l}\text { Audições didáticas para } \\
\text { introduzir a música; } \\
\text { Narração de contos; } \\
\text { Oficinas para divulgar, por } \\
\text { meio dos livros, diferentes } \\
\text { áreas do conhecimento, de } \\
\text { forma participativa e lúdica }\end{array}$ & $\begin{array}{l}\text { brincadeiras e interações das quais participa (EI01EO02). } \\
\text { Experimentar as possibilidades corporais nas brincadeiras e } \\
\text { interações em ambientes acolhedores e desafiantes } \\
\text { (EI01CG02). } \\
\text { Explorar diferentes fontes sonoras e materiais para acompanhar } \\
\text { brincadeiras cantadas, canções, músicas e melodias } \\
\text { (EI01TS03). } \\
\text { Utilizar sons produzidos por materiais, objetos e instrumentos } \\
\text { musicais durante brincadeiras de faz de conta, encenações, } \\
\text { criações musicais, festas (EI03TS01). } \\
\text { Manipular textos e participar de situações de escuta para } \\
\text { ampliar seu contato com diferentes gêneros textuais (parlendas, } \\
\text { histórias de aventura, tirinhas, cartazes de sala, cardápios, } \\
\text { notícias etc.) (EI02EF08). } \\
\text { Explorar o ambiente pela ação e observação, manipulando, } \\
\text { experimentando e fazendo descobertas (EI01ET03). }\end{array}$ \\
\hline $\begin{array}{l}\text { Antunes et al. } \\
\text { (2019) }\end{array}$ & $\begin{array}{l}\text { Utilização do RPG como } \\
\text { ferramenta de mediação da } \\
\text { leitura }\end{array}$ & $\begin{array}{l}\text { Conhecer e manipular materiais impressos e audiovisuais em } \\
\text { diferentes portadores (livro, revista, gibi, jornal, cartaz, CD, } \\
\text { tablet etc.) (EI01EF07). }\end{array}$ \\
\hline $\begin{array}{l}\text { Souza e } \\
\text { Gonçalves } \\
(2019)\end{array}$ & $\begin{array}{l}\text { Hora do conto; } \\
\text { Rodada poética; } \\
\text { Sessão de autógrafos; } \\
\text { Lançamento de livros; } \\
\text { Conversas literárias; } \\
\text { Palestras; } \\
\text { Projeto "Conversas } \\
\text { literárias - socializando a } \\
\text { leitura" } \\
\text { Espaço virtual dedicado } \\
\text { para as crianças, no qual são } \\
\text { postadas fotos da hora do } \\
\text { conto realizada. }\end{array}$ & $\begin{array}{l}\text { Participar de situações de escuta de textos em diferentes } \\
\text { gêneros textuais (poemas, fábulas, contos, receitas, quadrinhos, } \\
\text { anúncios etc.) (EI01EF08). } \\
\text { Interagir com outras crianças da mesma faixa etária e adultos, } \\
\text { adaptando-se ao convívio social (EI01EO06). } \\
\text { Dialogar com crianças e adultos, expressando seus desejos, } \\
\text { necessidades, sentimentos e opiniões (EI02EF01). } \\
\text { Conhecer e manipular materiais impressos e audiovisuais em } \\
\text { diferentes portadores (livro, revista, gibi, jornal, cartaz, CD, } \\
\text { tablet etc.) (EI01EF07). }\end{array}$ \\
\hline $\begin{array}{l}\text { Calheira, } \\
\text { Santos e Jesus } \\
(2020)\end{array}$ & Biblioterapia & $\begin{array}{l}\text { Comunicar suas ideias e sentimentos a pessoas e grupos } \\
\text { diversos (EI03EO04). } \\
\text { Respeitar regras básicas de convívio social nas interações e } \\
\text { brincadeiras (EI02EO06). }\end{array}$ \\
\hline $\begin{array}{l}\text { Santos, Souza } \\
\text { e Jesus (2020) }\end{array}$ & $\begin{array}{l}\text { Contação de histórias, } \\
\text { associadas à elaboração de } \\
\text { desenhos e pinturas pelas } \\
\text { crianças; } \\
\text { Peça teatral, que propicia a } \\
\text { produção de texto; } \\
\text { Exposição de filme; } \\
\text { Declamação de poema }\end{array}$ & $\begin{array}{l}\text { Traçar marcas gráficas, em diferentes suportes, usando } \\
\text { instrumentos riscantes e tintas (EI01TS02). } \\
\text { Criar movimentos, gestos, olhares e mímicas em brincadeiras, } \\
\text { jogos e atividades artísticas como dança, teatro e música } \\
\text { (EI03CG03). } \\
\text { Relatar experiências e fatos acontecidos, histórias ouvidas, } \\
\text { filmes ou peças teatrais assistidos etc.(EI02EF05). } \\
\text { Inventar brincadeiras cantadas, poemas e canções, criando } \\
\text { rimas, aliterações e ritmos (EI03EF02). }\end{array}$ \\
\hline $\begin{array}{l}\text { Targino } \\
(2020)\end{array}$ & $\begin{array}{l}\text { Biblioterapia; } \\
\text { Cine-pipoca; } \\
\text { Circuitos de oficinas; } \\
\text { Exposições; } \\
\text { Clubes de leitura literária; } \\
\text { Diários de leitura; } \\
\text { Disposição de jornais para } \\
\text { consulta diária; }\end{array}$ & $\begin{array}{l}\text { Demonstrar empatia pelos outros, percebendo que as pessoas } \\
\text { têm diferentes sentimentos, necessidades e maneiras de pensar } \\
\text { e agir (EI03EO01). } \\
\text { Relatar experiências e fatos acontecidos, histórias ouvidas, } \\
\text { filmes ou peças teatrais assistidos etc.(EI02EF05). } \\
\text { Interagir com crianças da mesma faixa etária e adultos ao } \\
\text { explorar espaços, materiais, objetos, brinquedos (EI01EO03). } \\
\text { Escolher e folhear livros, procurando orientar-se por temas e }\end{array}$ \\
\hline
\end{tabular}




\begin{tabular}{|c|c|c|}
\hline Autores & Práticas De Mediação & Prática Alinhada a BNCC \\
\hline & & $\begin{array}{l}\text { ilustrações e tentando identificar palavras conhecidas } \\
\text { (EI03EF03). } \\
\text { Formular e responder perguntas sobre fatos da história narrada, } \\
\text { identificando cenários, personagens e principais } \\
\text { acontecimentos (EI02EF04). } \\
\text { Produzir suas próprias histórias orais e escritas (escrita } \\
\text { espontânea), em situações com função social significativa } \\
\text { (EI03EF06). } \\
\text { Manusear diferentes portadores textuais, demonstrando } \\
\text { reconhecer seus usos sociais (EI02EF07). }\end{array}$ \\
\hline
\end{tabular}

Fonte: Dados da pesquisa (2020).

Observa-se que as práticas mais comuns são as contações de histórias (4 atividades), hora do conto (4 atividades), exposições de filmes (4 atividades) teatros (4 atividades) e oficinas (5 atividades).

Recreação, oficinas, exposições e palestras também são empregadas no cotidiano destas instituições, voltados para a divulgação da cultura local. Seguindo de atividades como sessão de autógrafos, lançamentos de livros e encontro com autores, familiarizando os usuários com este universo dos escritores e suas obras, com foco nos escritores da própria comunidade, valorizando e difundindo o trabalho realizado na região, assim como as feiras literárias.

A programação voltada para a socialização de obras fica direcionado aos cafés literários, clube do livro, roda de leitura e diário de leitura. Apesar de aparentar serem focadas a usuários alfabetizados, estas atividades podem ser realizadas por todas as faixas etárias, pois a leitura literária não se dá apenas pela palavra escrita, mas sim também pelas ilustrações, pela audição das obras, através da exploração do próprio objeto livro.

Algumas práticas menos comuns estão surgindo, como a utilização do RPG, que, através de um mediador leitor, pode ser jogado por todas as faixas etárias. A biblioterapia está entrando na lista de atividades rotineiras, também uma prática voltada a todas as idades. Uma atividade menos comum foi a musicalização, que, apesar de ser um instrumento muito utilizado com crianças, está em falta nas bibliotecas escolares.

Apenas um artigo trouxe práticas que são voltadas exclusivamente ao público alfabetizado, no estudo de Gomes e Santos (2014), que apresentam práticas como levantamento bibliográfico, treinamento para uso de bases de dados e workshops. Atividades como estas são incluídas na BNCC, dentro das 10 competências gerais e são fundamentais em bibliotecas escolares, porém a um grupo de estudantes diferentes do foco deste estudo, como os alunos do ensino médio.

InCID: R. Ci. Inf. e Doc., Ribeirão Preto, v. 12, n. 2, p. 89-108, set. 2021./fev. 2022. 
Analisando o quadro 3 e voltando o olhar para o público infantil de 0 a 5 anos, percebese que são poucas as atividades de mediação da literatura voltadas exclusivamente a eles. No entanto as práticas abordadas no quadro podem ser adaptadas a este público, dessa forma, é entendido que ações associadas a mediação para a primeira infância se torna indispensável, considerando a mediação como principal forma de inclusão das crianças neste ambiente.

Compreende-se que a biblioteca escolar faz parte de uma rede de ensino e que este tem como respaldo a Base Nacional Comum Curricular, que busca o desenvolvimento integral da criança, elencamos no quadro acima as práticas alinhadas ao desenvolvimento integral, relacionando os cinco campos de experiências: 1) o eu, o outro e o nós; 2) corpo, gestos e movimentos; 3) traços, sons, cores e formas; 4) escuta, fala, pensamento e imaginação; 5) espaços, tempo, quantidades, relações e transformações. Direcionando os objetivos de cada campo, é possível identificar os entrelaces nas atividades desenvolvidas nas bibliotecas com os objetivos da BNCC para o desenvolvimento integral das crianças de 0 a 5 anos, como mostra o quadro 3.

Sendo assim, conforme a Federação Internacional de Associações e Instituições Bibliotecárias (IFLA), em seu manifesto para biblioteca escolar, "a biblioteca escolar habilita os estudantes para a aprendizagem ao longo da vida e desenvolve a imaginação, preparando-os para viver como cidadãos responsáveis" (IFLA, 2000, p. 1) o que vem ao encontro com a proposta de formação integral da BNCC.

Ainda de acordo com o documento, a maioria dos objetivos da biblioteca escolar é voltada a formação dos sujeitos, como

oferecer oportunidades de vivências destinadas à produção e uso da informação voltada ao conhecimento, à compreensão, imaginação e ao entretenimento; apoiar todos os estudantes na aprendizagem e prática de habilidades para avaliar e usar a informação, em suas variadas formas, suportes ou meios, incluindo a sensibilidade para utilizar adequadamente as formas de comunicação com a comunidade onde estão inseridos; organizar atividades que incentivem a tomada de consciência cultural e social, bem como de sensibilidade (IFLA, 2000, p. 2)

Desta forma, percebe-se que existe um conjunto que envolve práticas e documentos oficiais para embasar o trabalho nas bibliotecas escolares e que estas bibliotecas, agindo de acordo com a instituição escolar que está inserida, tem o papel de desenvolver e oferecer para as crianças a possibilidade de se tornarem pensadores críticos e efetivos usuários da informação, em todos os formatos e meios (IFLA, 2000). 


\section{Considerações finais}

Esta pesquisa possibilitou a investigação de documentos que construíram, aliados às concepções teóricas, a análise de que a literatura infantil pode contribuir no desenvolvimento da criança. Compreendendo a BNCC para educação infantil, percebeu-se que a literatura está envolvida em todos os campos de experiências, sendo assim, ela é fundamental para o desenvolvimento integral.

Tendo em vista os estudos recuperados com o propósito de descrever práticas de mediação e conceituar os termos mediação da leitura e literatura, verificou-se resultados incipientes, muitas vezes os conceitos são apresentados como sinônimos. No entanto, foi possível identificar que são práticas diferentes, enquanto a mediação da leitura é direcionada para práticas de alfabetização, a mediação da literatura é voltada para aspectos de conhecimento cultural, desenvolvimento crítico e lazer, que não necessitam a alfabetização, o que acontece com o público-alvo deste estudo, as crianças de 0 a 5 anos.

Entretanto, com as informações obtidas sobre as práticas de mediação em bibliotecas, entendeu-se que a maioria não são voltadas exclusivamente para as crianças desta faixa etária, no entanto podem ser adaptadas e desenvolvidas com este público.

Apesar de não serem alfabetizadas, a mediação pode ocorrer por intermédio do contato com o objeto livro para os bebês, através do tato podem explorar este material e se expressar através dos balbucios, como pede no objetivo EI01EO04: comunicar necessidades, desejos e emoções, utilizando gestos, balbucios, palavras. Já as crianças bem pequenas, através da leitura de imagens podem criar suas próprias histórias e recontá-las, como explorado no objetivo EI02EF06: criar e contar histórias oralmente, com base em imagens ou temas sugeridos. E assim o bibliotecário vai realizar a mediação utilizando os objetivos propostos na BNCC em suas ações voltadas a este público.

Vale destacar que a biblioteca escolar deve estar também presente no Projeto Político Pedagógico da escola a qual faz parte, para que possa desenvolver seu trabalho de acordo com os ideais da instituição, oferecendo serviços que podem contribuir diretamente em toda comunidade escolar.

Enfim, com vistas o objetivo geral deste estudo, certamente a literatura infantil em seu sentido amplo, além do texto escrito, pode contribuir com o desenvolvimento integral da 
criança, ao considerar o trabalho de mediação de bibliotecárias e bibliotecários dentro da biblioteca escolar, em consonância com a base nacional comum curricular e com práticas significativas que vão trazer novas experiências a fim de proporcionar o crescimento da criança em seus diversos âmbitos, como o social e cognitivo, para contribuir com desenvolvimento integral.

\section{Referências}

ABRAMOVICH, Fanny. Literatura infantil: gostosuras e bobices. São Paulo: Scipione, 1989.

AMARO, Vagner da Rosa; ALENCAR, Patrícia Vargas. Práticas de mediação da leitura em bibliotecas da rede SESC. In: ENCONTRO NACIONAL DE PESQUISA EM CIÊNCIA DA INFORMAÇÃO, 28., 2017. Anais... 2017. Disponível em:

http://hdl.handle.net/20.500.11959/brapci/104748. Acesso em: 25 dez. 2020.

ANTUNES, Jeferson et al. Jogos cooperativos e mediação da leitura: por que não na biblioteca pública? Perspectivas em Ciência da Informação, v. 24, n. 4, p. 3-24, 2019.

Disponível em: http://hdl.handle.net/20.500.11959/brapci/126859. Acesso em: 25 dez. 2020.

BARROS, Maria Helena Toledo Costa de. A mediação da leitura na biblioteca. In: BARROS, Maria Helena Toledo Costa de. Leitura: mediação e mediador. São Paulo: FA, 2006. p. 1722.

BORTOLIN, Sueli; ALMEIDA JUNIOR, Oswaldo Francisco de. Oralidade e a ética na mediação da literatura. Informação \& Informação, Londrina, v. 19, n. 2, p. 171-190, 2014. Disponível em: http://www.uel.br/revistas/uel/index.php/informacao/article/view/13902. Acesso em: 25 dez. 2020.

BRASIL. Base Nacional Comum Curricular. Brasília: MEC, 2017. Disponível em: http://basenacionalcomum.mec.gov.br/images/BNC C_20dez_site.pdf. Acesso em: 25 dez. 2020.

BRASIL. Lei de Diretrizes e Bases da Educação Nacional, LDB. 9394/1996. São Paulo: Saraiva, 1996.

CALHEIRA, Fausto José Silva; SANTOS, Raquel do Rosário; JESUS, Ingrid Paixão de. Entrelaces entre mediação da leitura e a biblioterapia como ações de integração social na terceira idade. Revista ACB: Biblioteconomia em Santa Catarina, Florianópolis, v. 25, n. 1, p. 3-20, 2020. Disponível em: http://hdl.handle.net/20.500.11959/brapci/137966. Acesso em: 25 dez. 2020.

COSTA, Aline Cristina Chanan; SANTOS NETO, João Arlindo. Brinquedotecas e ludotecas: ambientes para a mediação da leitura no Paraná. Revista ACB: Biblioteconomia em Santa Catarina, Florianópolis, v. 21, n. 2, p. 359-380, 2016. Disponível em: http://hdl.handle.net/20.500.11959/brapci/69011. Acesso em: 25 dez. 2020. 
FLECK, Felícia de Oliveira. Uma percepção das visitas às bibliotecas públicas de Barcelona (ES): experiências formativas. Revista ACB: Biblioteconomia em Santa Catarina, Florianópolis, v. 23, n. 3, p. 502-509, 2018. Disponível em: http://hdl.handle.net/20.500.11959/brapci/109183. Acesso em: 25 dez. 2020.

FLECK, Felícia de Oliveira; CUNHA, Miriam Figueiredo Vieira da; NAVARRA, Maite Comalat. A contação de histórias nas bibliotecas públicas de Barcelona: impressões de viagem. Informação \& Informação, Londrina, v. 23, n. 3, p. 696-707, 2018. Disponível em: http://www.uel.br/revistas/uel/index.php/informacao/article/view/27951. Acesso em: 25 dez. 2020.

FREIRE, Paulo. A importância do ato de ler: em três artigos que se completam. 22. ed. São Paulo: Cortez, 1988.

GIL, Antonio Carlos. Como elaborar projetos de pesquisa. 4. ed. São Paulo: Atlas, 2002.

GOMES, Henriette Ferreira; SANTOS, Raquel do Rosário. Atividades de mediação para leitura e escrita: uma análise dos níveis de mediação em experiências realizadas por bibliotecas de universidades públicas. Revista Ciência da Informação, Salvador, v. 43, n. 2, p. 257-271, 2014. Disponível em: http://revista.ibict.br/ciinf/article/view/1408. Acesso em: 25 dez. 2020.

IFLA - Federação Internacional de Associações e Instituições Bibliotecárias. Manifesto IFLA/UNESCO para biblioteca escolar. São Paulo: 2000. Disponível em:

https://www.ifla.org/files/assets/sc.hool-libraries-resource-centers/publications/school-librarymanifesto-pt-brazil.pdf. Acesso em: 25 dez. 2020.

INSTITUTO PRÓ-LIVRO. Retratos de leitura no Brasil. 5. ed. Brasília: Itaú Cultural, 2020. Disponível em: https://prolivro.org.br/wpcontent/uploads/2020/09/5a_edicao_Retratos_da_Leitura_no_Brasil_IPL-compactado.pdf. Acesso em: 25 dez. 2020.

LAJOLO, Marisa; ZILBERMAN, Regina. Literatura infantil brasileira: história e histórias. 6. ed. São Paulo: Ática, 1999.

MARCONI, M., LAKATOS Eva Maria. Técnicas de pesquisa. 5. ed. São Paulo: Atlas, 2002.

MORO, Eliane Lourdes da Silva; ESTABEL, Lizandra Brasil. A mediação da leitura na família, na escola e na biblioteca através das tecnologias de informação e de comunicação e a inclusão social das pessoas com necessidades especiais. Inclusão Social, Brasília, v. 4, n. 2, p. 68-81, jun. 2011. Disponível em: http://hdl.handle.net/20.500.11959/brapci/101251. Acesso em: 25 dez. 2020.

PIAGET, Jean. O nascimento da inteligência na criança. 4. ed. Rio de janeiro: Zahar, 1973.

RASTELI, Alessandro; CAVALCANTE, Lídia Eugênia. Mediação cultural e apropriação da informação em bibliotecas públicas. Encontros Bibli: Revista Eletrônica de Biblioteconomia e Ciência da Informação, Florianópolis, v. 19, n. 39, p. 43-58, 2014. Disponível em: https://www.redalyc.org/pdf/147/14730602004.pdf. Acesso em: 25 dez. 2020. 
REYES, Yolanda. A casa imaginária: leitura e literatura na primeira infância. São Paulo: Global, 2010.

SANTOS, Raquel do Rosário; SOUSA, Ana Claudia Medeiros de; JESUS, Ingrid Paixão de. Lapidação de mediadores de leitura e sujeitos leitores para o protagonismo social. Revista Ibero-Americana de Ciência da Informação, Salvador, v. 13, n. 1, p. 56-72, abr. 2020. Disponível em: https://periodicos.unb.br/index.php/RICI/article/view/22932. Acesso em: 25 dez. 2020.

SILVA, Aparecida de Almeida da. As livrarias como espaço de mediação de leitura. Biblos: Revista do Instituto de Ciências Humanas e da Informação, Rio Grande, v. 23, n. 2, p. 117 126, 2009. Disponível em: http://hdl.handle.net/20.500.11959/brapci/24265. Acesso em: 25 dez. 2020.

SILVA, Ezequiel Theodoro. Elementos da pedagogia da leitura. 3. ed. São Paulo: Martins Fontes, 1998. 140p.

SOUZA, Edivanio Duarte de. Dinamização e mediação na biblioteca escolar: potencialidades da leitura literária. Ciência da Informação em Revista, Maceió, v. 1, n. 2, p. 3-8, ago. 2014. Disponível em: http://hdl.handle.net/20.500.11959/brapci/36065. Acesso em: 25 dez. 2020.

SOUZA, Franciny Bom Reis de; GONÇALVES, Renata Braz. Práticas de incentivo à leitura em livrarias gaúchas: livraria exercendo papel de bibliotecas? Revista ACB: Biblioteconomia em Santa Catarina, Florianópolis, v. 24, n. 1, p. 33-49, 2019. Disponível em: http://hdl.handle.net/20.500.11959/brapci/112508. Acesso em: 25 dez. 2020.

TARGINO, Maria das Graças. Mediação cultural e da leitura como estratégia de inclusão social: bibliotecas comunitárias. Revista Brasileira de Biblioteconomia e Documentação, São Paulo, v. 16, p. 1-17, 2020. Disponível em: http://hdl.handle.net/20.500.11959/brapci/141204. Acesso em: 25 dez. 2020.

VYGOTSKY, Lev Semionovitch. A formação social da mente: o desenvolvimento dos processos psicológicos superiores. 7. ed. São Paulo: Martins Fontes, 2007. 